\section{Norway unveils design of 'doomsday' seed bank}

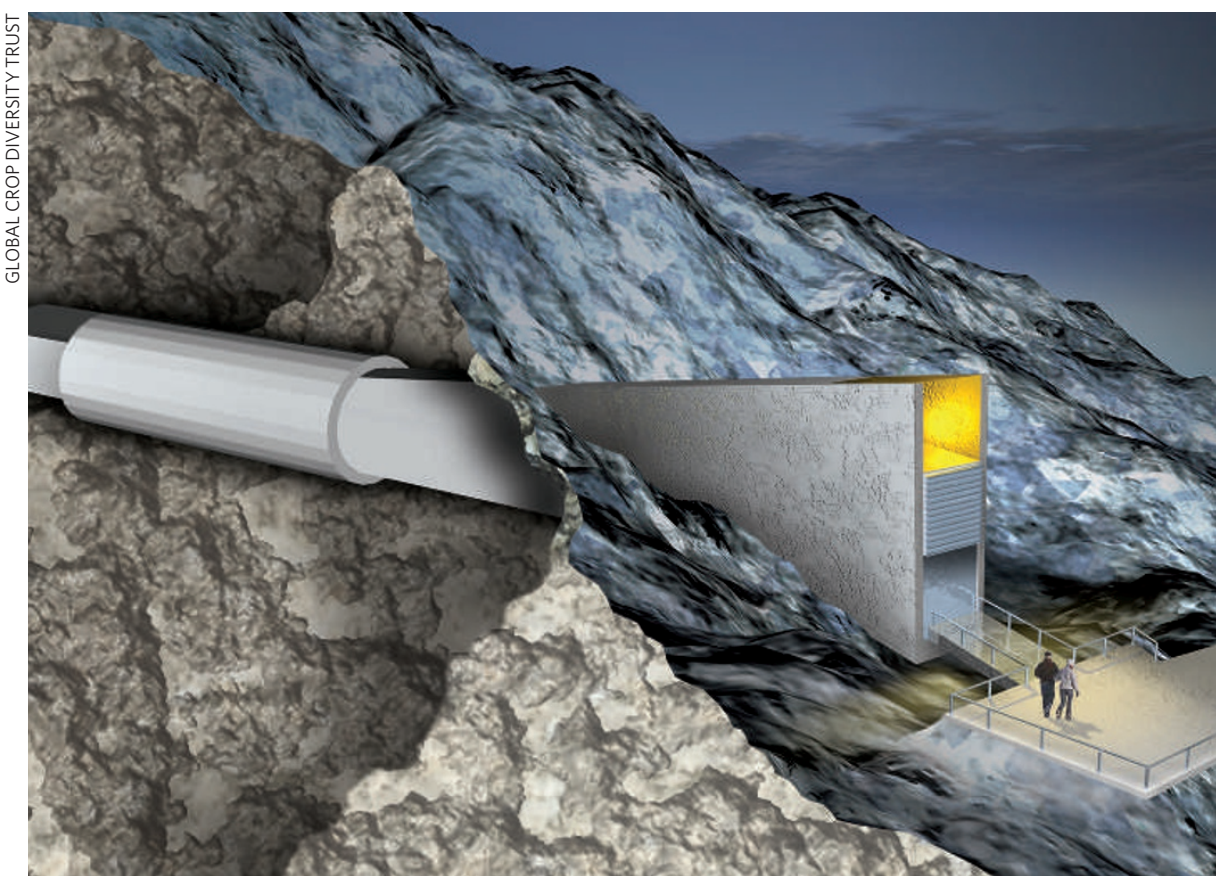

The Svalbard International Seed Vault will offer a safe haven for some 1.5 million crop strains.

The Arctic outcrop of Svalbard, just a few hundred miles from the North Pole, might seem like an odd place to install a freezer. But buried deep in the interior of an Arctic mountain, a US\$5-million cold storage unit will house duplicate seeds for almost all of the world's estimated 1.5 million crop strains - protecting them from the ravages of such disasters as war and climate change.

The Norwegian government last week unveiled its design for the Svalbard International Seed Vault, nicknamed the 'doomsday vault' by the popular press. Construction should be completed in September, with the first seed deliveries arriving in March 2008.

Set at the end of a 120-metre tunnel cut into the freezing rock, where the natural temperature is $-6^{\circ} \mathrm{C}$, the facility will be further cooled to $-18^{\circ} \mathrm{C}$. "It will offer the best conditions for seed storage on Earth," says Cary Fowler, head of the Global Crop Diversity Trust, which will provide the facility's $\$ 125,000$-a-year operating costs. The vault will even be insulated against climate change, says Fowler. Set 130 metres up the mountainside, it will be able to survive the most catastrophic projected rises in sea level.

Despite these precautions, calling the facility a 'doomsday vault' is disingenuous, argues Andreas Graner, who helps to run a seed bank at the Leibniz Institute of Plant Genetics and Crop Plant Research in Gatersleben, Germany. Even with optimal storage, most seeds lose their ability to germinate after about 20 years, so the facility is unlikely to bail out the human race from global disasters that might happen centuries in the future. To keep crop strains for long periods of time, seeds must be regularly grown
"The vault will offer the best conditions for seed storage on Earth." into plants and a new generation of seeds produced.

Although it will take more than a secure vault to save us from a global catastrophe, Fowler says it will act as a "global insurance policy", holding crop strains in the event that banks elsewhere are destroyed by local disasters. It will open for several weeks every year to take delivery of new strains from many of the 1,400 crop repositories around the world. In future, seeds lost in disasters like Typhoon Durian, which washed away samples in Jakarta, Indonesia, or in looting, as has occurred in Iraq and Afghanistan, can be replaced by dipping into the Svalbard vault.

Michael Hopkin
ON THE RECORD

\section{c(Sometimes you don't really trust men to pick out things you'll want to wear - I was very pleasantly surprised."}

Harvard Medical School's Laura Mariani after her boyfriend bought her some molecule-shaped earrings (one serotonin, one dopamine) from jewellery company Made With Molecules. One to consider if you messed up on Valentine's Day.

\section{SCORECARD}

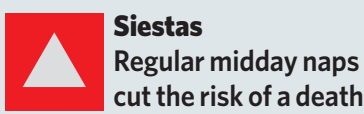

from heart disease by up to $64 \%$, says a study of Greek men. The effect was strongest in those with jobs, highlighting the stressbusting power of a nice nap.

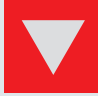
Science books Ten years ago, Britain's most popular non-

fiction library book was Stephen Hawking's seminal A Brief History of Time. Now it's You Are What You Eat, a dieting tome by the widely criticized 'holistic nutritionist' Gillian McKeith.

\section{NUMBER CRUNCH}

$90 \%$ is the degree of certainty that global warming is being caused by human activity, according to the Intergovernmental Panel on Climate Change's fourth assessment report.

$95 \%$ of Democrats who responded to a limited poll of both parties in Congress said they believed that it has been proved beyond reasonable doubt that human activities are warming the planet.

$13 \%$ is the proportion of Republicans who responded who share that view.

Sources: Archives of Internal Medicine, $B B C$, IPCC, The Scientist 